\title{
A Culture of Indignity and the Failure of Leadership
}

\author{
Donna Hicks ${ }^{1}$
}

Received: 15 February 2016 / Accepted: 6 May 2016/Published online: 8 August 2016

(C) Springer International Publishing 2016

\begin{abstract}
This paper uses a dignity lens to examine the collapse of a major US corporation. The company was experiencing a significant breakdown in its relationships with its unions, creating hostility, unrest and mistrust among its employees. The paper describes the assessement and dignity intervention that was used to repair the broken relationships between management and its unions and to heal the "culture of indignity" that was fueling the conflicts.
\end{abstract}

Keywords Dignity C Culture of indignity · Leadership failure

\section{Introduction}

A few years ago, I received a surprising call from a business consultant who was working with a major US Corporation. He was trying to help them resolve some intractable conflicts between the management of the company and its unions. They had exhausted many of the traditional methods of conflict resolution. None of the approaches was successful at getting to the root of the problem. While I was listening to the consultant describe what was going on within the organization, I couldn't help but wonder why he was calling me. At the time, all of my work focused on international conflicts such as the Israel/Palestine, Sri Lanka, Colombia, Northern Ireland, Libya, Syria and others. Why would this business consultant be calling me?

It didn't take long to understand what the consultant had in mind. He had been asked by senior management to find a creative approach to conflict resolution. The consultant came across my international dignity work and was convinced that dignity issues were creating and fueling most of the conflicts that he was seeing in the company.

I had recently written the book, Dignity: Its Essential Role in Resolving Conflict, which concretely operationalized the elements of dignity (what it looks like to honor peoples' inherent value and worth) (Hicks 2011). The book was inspired by my 25 years working as a third party in many of the world's intractable conflicts. I felt that my exposure to these conflict dynamics helped me see a missing link in our understanding of how to resolve them. I

Donna Hicks

dhicks@wcfia.harvard.edu

1 Harvard University, 1737 Cambridge Street, Cambridge, MA 02138, USA 
saw a common thread among all of the conflicts; that underlying the political issues that divided the parties were always unaddressed, unhealed wounds to peoples' dignity - to their inherent value and worth. ${ }^{1}$ The book highlighted this human dimension to conflict- the universal desire to be treated as something of value.

The consultant was particularly convinced that the underlying issue of identity (one of the ten elements of dignity) - the lack of acceptance and recognition of the important role the employees played in the success of the company-were key drivers of the conflicts. This was just the tip of the dignity iceberg. The more we talked, the clearer it became that longstanding, unaddressed, festering issues of unacknowledged dignity violations were not only creating problems with the employees, but were contributing to an overall culture within the organization that had become toxic. Would the Dignity Model be useful in addressing the dysfunctional culture of indignity that the consultant had described?

My curiosity had been piqued. I had never thought much about applying the Dignity Model to conflicts other than in the international arena. The more I listened to the consultant describe the specific issues that were problematic within the company, I quickly realized that the issue of dignity was not just applicable to political issues that arise when communities and nations are embroiled in disputes, but that it was a human issue.

Wherever human beings cluster and coexist, concerns about the way people are treated arise at the drop of a hat. Dignity violations occur in marriages, families, extended families, the workplace, communities, organizations, schools and universities, health care, faith communities, and other places were people organize. I know because now, in 2016, I have consulted in all of these diverse arenas.

When I wrote the book, Dignity, I never imagined it would hit a nerve for so many people. I also found that it resonated in all parts of the world. The book has now been translated into several languages. The human concern about dignity - about wanting to be treated as if we mattered-is as true in Asia and Africa as it is in South America and North America and all over the world. We all want to be treated as if we were valuable and worthy, no matter our cultural differences. We all yearn to be treated with dignity; it is our highest common denominator.

After about an hour on the phone with the consultant, I had agreed to meet with a Senior VP in the organization in order to discuss the role dignity (or indignity) might be playing in the breakdown of the relationships between management and its unions. Within a couple of weeks I was sitting at a table with the consultant and the Senior VP, discussing my work and how the Dignity Model might be used in addressing the conflicts that plagued the organization. It didn't take long to agree to a work plan. The VP assigned me and the consultant to try the Dignity Model out in one work group that was having a conflict to test the usefulness of the approach.

\section{The Backdrop: the Problem with Solutions}

Before explaining the step-by-step process that I use when consulting with the Dignity Model, I'd like to briefly outline what I typically encounter when I start to work with an organization.

As is always the case, organizations in trouble are quick to focus on the solutions to their problems. They want results, especially when paying expensive consultants to address their conflicts. I understand their desire for results, but I have learned that it is often part of the problem.

The first thing I tell clients is that we have to understand the problem before we can solve it. A company's desire to rush to solutions before they understand the source of the problem is a

\footnotetext{
${ }^{1}$ People often confuse dignity with respect. The difference is that dignity (our inherent value and worth) is something everyone is born. Respect, on the other hand, has to be earned.
} 
common and understandable mistake. Of course leaders want to bring an end to the disputes that are plaguing their organizations. The problem with not taking the time to accurately identifying the root cause of the conflict is that they end up asking the wrong questions, which lead to the wrong answers, which lead to the wrong solutions.

If leaders are seeking answers to the wrong questions then the results they will get will not create the kind of change they desire. In this case, and in most cases, the underlying problem was about the unions feeling they were being treated badly. It was about the multitude of ways that employees felt violated on a regular basis. The conversation they needed to start with was not about how to solve the problem, but about what they were doing that was creating the problem.

This step, in itself, can be difficult for those in leadership positions because it means they have to accept the fact that they may be dignity violators. The resistance to taking responsibility for mistreating others is often the greatest obstacle to repairing relationships. It is hard for leaders to admit to making mistakes and even harder to accept that their mistakes have led to the breakdown of important employee relationships.

The shame associated with accepting responsibility for one's hurtful actions is one of the greatest leadership challenges I face in my work. Getting people to hold up the mirror and accept what they have done, requires overcoming some powerful self-preservation instincts that protect them from looking bad in the eyes of others (Sheff and Retzinger 1991).

In summary, accurately assessing the nature of the problem organizations are facing from a dignity perspective requires committed leadership; leadership that is willing to embrace the dignity work and to accept responsibility for both the cause and the solution to the problem. As you will see, in this case, I did not have the key decision-makers on board when I started the project, which proved to seriously undermine the intervention in the end. No matter whether leaders are looking to create a culture of trust from the start of an organization or are trying to rectify a toxic existing culture, an understanding of dignity must be an essential component of their leadership approach.

\section{What a Dignity Intervention Looks Like}

\section{Step One: Dignity 101: Introduction to the Dignity Model}

The first thing I do when introducing the Dignity Model to an organization is to introduce the basic building blocks of the approach. In this case we were specifically focusing on how to make dignity a way of life in the workplace, but the learning does not begin and end when one goes to work. Knowledge about dignity is not just a set of tools one acquires and pulls off the shelf when the need arises. Dignity transforms the way we understand ourselves, others and the world around us. It is the lens through which we develop relationships and make sense of our lives. It is the platform from which we understand our deepest desires and purpose.

Learning about dignity is more than a collection of facts and information. The knowledge that is gained will not solve technical problems-it is about solving problems that we face by virtue of being human. Dignity consciousness is more about being wiser than smarter, especially when it comes to human relations.

The goal of Step One is to understand the building blocks of the Dignity Model:

- Learning what dignity is (it is different from respect).

- Learning the neuroscience of dignity (how our brain is wired to react to dignity violations) 
- Learning the ten elements of dignity (See Appendix)

- Learning the Ten Temptations to Violate Dignity (See Appendix)

- Learning how to rebuild a broken relationship using a dignity process

After the "Dignity 101" introduction is completed, I move on to interviewing managers and their direct reports in order to conduct a dignity assessment. I am interested in understanding the type of dignity issues that are at play in the work environment, both dignity violations and the ways people feel their dignity is honored.

\section{Step Two: Conducting a Dignity Assessment}

\section{Identifying the Core Issues}

I typically start a project by asking about the way people feel working for the company. I soon discover that in a toxic, dignity-violating culture, there are tidal waves of anger and resentment. People who feel violated have a strong need to tell their story. If they perceive they have a trustful listener, they will make themselves vulnerable by telling the truth about what they have endured.

At the end of the interviews, I often hear an added indignity. Typical closing remarks are, "Well, that's just the way it is. We have to suck it up and keep our heads down." The resignation is ubiquitous, as if there were nothing to be done. "It is what it is," is the common lament.

It may not come as a surprise to learn that in every organization where I have consulted in the past several years, most people were never exposed to the concept of dignity and the role it plays in the workplace. Once they are introduced to the basic building blocks of dignity, people say to me, "This is our problem. How did we go so long without talking about this? We felt it but never put words to it."

It usually doesn't take long to convince people that dignity (or indignity) is playing a role in problems that the organization is facing. Once the issues are brought to their attention, they see the effects of indignity very quickly. The biggest hurdle is getting the leadership to accept the important role dignity plays in creating an environment where everyone feels seen, heard, appreciated and valued for his or her contributions to the organization.

While collecting the stories from both managers and their direct reports on ways in which they feel their dignity is honored and violated in the organization, I always keep in mind the two levels at which dignity issues usually manifest: Interpersonally and systemically.

At the interpersonal level, I am concerned with finding out the ways in which the managers and their direct reports interact. I ask directly, "What are the ways in which you feel your dignity is honored by your boss and in what ways do you feel that your dignity is being violated?" On the other hand, at the systemic level, I am interested in identifying polices and procedures that are put in place by the executive leadership team that are either dignity honoring or dignity violating. For example, if a policy discriminates employees because of some aspect of their identity (race, religion, ethnicity, sexual orientation, disability, etc.,) then it would be described as a dignity violating policy.

\section{Step Three: Implementing Steps Toward Creating a Culture of Dignity}

The key objective in the implementation phase is supporting managers and employees in correcting the dignity violations, as well as increasing the honoring of dignity. Another goal is 
to normalize the dignity learning and skill application, both interpersonally and systemically, especially for the senior management and managers.

For example, at the interpersonal level, knowing how to honor dignity and to redress dignity violations; how to engage in a process of relationship repair when breakdowns occur; how to give and receive feedback about your behavior, how to defend your dignity without returning the violation, and knowing how to hold oneself accountable when one violates dignity, all need to be a normal part of leading. Systemically, the goal is to be able to develop policies that are honoring of dignity and to become aware of what not to do to avoid alienating the workforce.

\section{Step Four: Creating a Dignity Leadership Team}

Finally, an in-house dignity leadership team is established to handle dignity issues as they arise. This team is responsible for creating a Dignity Code of Ethics for the organization, which every employee signs on to and aspires to maintain.

\section{Assessing the Dignity Intervention: Did it Work?}

Before starting my intervention with the work group that the Senior VP had suggested, I paused. I told the consultant with whom I was working that I felt uncomfortable that I hadn't had a chance to meet with other members of the executive leadership team-particularly the CEO-to discuss my ideas about how to turn the troubled relationships around between management and the unions. I knew that if we were going to address the root causes of the conflict, people in decision-making roles needed to be on board.

I felt certain that part of the problems the organization faced were systemic in nature - that there were dignity violating policies that most likely had not been examined and addressed. The consultant discouraged me from making too much of a fuss about not meeting the CEO, instead encouraged me to do the pilot test of the dignity approach with the designated work group and then take our "success story" to the senior leadership team. I reluctantly agreed and started a 6-month intervention with Work Group A.

\section{Assessment Results}

The initial phase of Work Group A's intervention was more than welcomed by the managers and their direct reports. They told me privately and publically that finally, someone was giving them an opportunity to discuss the "elephant in the room." As eager as they were to talk about the multitude of ways that they felt violated by the senior executive leadership team, they were also wary that "telling their stories" would get them into trouble. They did not trust that the company wanted to address the "real" problems.

I was in an unusual position: I needed to acknowledge their fears and concerns and at the same time, I had to tell them that I was hired by a senior VP to do the dignity intervention. I had to reassure them that I would not attribute any information from them that would make them vulnerable. Nonetheless, people were torn between wanting to talk and tell their stories and their fears that they would lose their jobs as a result. There was no trust whatsoever between them and the leadership.

I convinced them that I would be the repository of trust for them - that I would do nothing to put them in harm's way. I explained that I would try my best to deliver my findings to the 
leadership so that they could feel hopeful that they would experience the much-needed change in the way they were treated. I am often asked why I was able to convince the people I interviewed that they could trust me, especially given the culture of distrust that permeated the organization.

One of the strengths of the Dignity Model is that by delivering the Dignity 101 aspect of the intervention as the first stage of the work, I have an opportunity to develop a genuine relationship with the people. I do not begin by asking them to discuss painful stories or to reveal something that they do not feel comfortable discussing. Instead, I begin by introducing the building blocks of dignity, as if I were teaching a class.

After a month of working with Work Group A on the introduction to the Dignity Model, they got to know me and felt not only were they learning something of value, but that I had named the problem from which they were all suffering. They resonated so strongly with the dignity framing of the issues they faced, they were ready to talk about their own dignity violations. They did develop trust in me but perhaps more important, they also trusted the approach.

Before I describe the specific interpersonal indignities that were revealed within Work Group A, I'd like to explain the broader, systemic issues that I uncovered during my assessment. The systemic indignities created the context for the one-on- one violations many of the members of the work group experienced.

\section{The Systemic Narrative of Betrayal and Injustice}

There was a shared narrative that I heard over and over again about the systemic dignity violations perpetrated by the senior leadership team. The big story had to do with a sense of betrayal and injustice experienced by the employees over a collective effort to avoid bankruptcy a few years before my arrival. The employees were asked by management to take pay cuts in an effort to keep the company viable, to which everyone agreed. The idea was to "pull together and win together." Everyone was sacrificing for the greater good of the company.

Approximately 5 years after all employees took their pay cuts, the senior leadership team gave themselves big bonuses after an unexpected rise in the company stock. Nothing was distributed to the rest of the employees. People were outraged beyond words. What happened to pull together, win together? The sense of injustice permeated the culture overnight. The senior leadership team exclaimed that it was in their contracts to take the bonuses. They tried to justify their actions but it fell on deaf ears.

What made matters worse; the issue was never properly discussed with the workforce. When I arrived about 4 years later, the employees were still fuming. It was the grand narrative of betrayal and injustice that was kept alive by the silence of the executive leadership team. The fragile bond of trust that was the basis of "pull together-win together" was shattered. There was an all out war between the unions and the management.

Another aspect of the narrative had to do with not being valued for the contribution the workers were making to the company. They felt their roles and identities were not being recognized, acknowledged or understood. "How could they possibly think that it wouldn't affect us when they took those bonuses? Didn't they care about how we would react?" I heard this over and over again.

The employees felt a disconnect between them and the senior leadership team. They felt that the leadership had tucked themselves away in an area of corporate headquarters that was separate from much of the workforce-there was even a security guard who 
questioned anyone who entered the area. Employees felt excluded from the daily activities of the leadership team. As a result, the lack of trust in the leadership team had reached an all time high. Any attempt to address the problems in the relationship with their unions failed. All of their interactions were adversarial, only deepening the rifts between them.

The systemic narrative was the backdrop to all of the other dysfunctional dynamics observed in the organization. Employees just couldn't let go of their outrage about the bonuses. Even if their contract stated that management was legally justified to take them, it's hard to imagine how they failed to predict the consequences of their actions on the employees. I heard countless times, "Just because it's legal doesn't mean it's right."

\section{Interpersonal Narratives}

After everyone in the Work Group had completed "Dignity 101," I set up individual interviews with both the managers and their direct reports. Using the Ten Elements of Dignity as a guide, I asked everyone to tell me the ways in which they felt their dignity was honored and violated in their work group.

While all of the elements of dignity were involved in the stories I heard, the single most common dignity violation reported was the element of safety. No one felt safe to speak up when his or her dignity was violated. When I asked what they were afraid of, they looked at me and said, "It would be career suicide if I spoke up to my boss." People were concerned about their performance reports. They felt that their bosses would give them a bad review if they confronted them.

This resulted in many employees who were enduring dignity violations on a daily basis with nowhere to turn for help. Worse yet, the level of resentment felt by the direct reports was significant. When people feel that they are not treated well and can't do anything about it, the result is a work environment that does not feel safe, much less productive.

The other thing that happens routinely is that gossip dominates the day-to-day communication culture. When people do not feel safe to speak up, then they go underground with their stories. The gossip network is active and alive while healthier forms of communication are non-existent. Giving each other feedback about their dignity violating behaviors was viewed as more threatening than enduring the violation. Fear of confrontation was pervasive.

I would like to make clear that the managers I interviewed were often not aware of the violations they were perpetrating on their teams. These were good people who were simply not educated about dignity and had no idea of the ways in which they were causing harm to their teams. While the ignorance is understandable (where does anyone learn about dignity as part of leadership training?), it wreaks havoc on relationships.

\section{Adding Insult to Injury}

The one-on-one interviews revealed other collective dignity violations. Employees who publically expressed their anger and disappointment to the leadership team expected that their grievances would be addressed. As I mentioned above, the senior leadership team remained silent about the executive compensation. There was no opportunity for discussion - to be heard or listened to - and more importantly to them, there was no apology for what they perceived as gross unfairness and betrayal. They wanted accountability and it never happened. 
The bitterness and resentment grew to the extent that the unions went public with their outrage. They rented billboard space on major highways that displayed scathing attacks on the senior management team.

My sense was that a threshold had been crossed and there was no turning back. After working with my initial intervention with Work Group A, I continued the work with dozens of other work groups, especially where dignity violations abound. We called them 'Dignity Hot Spots." While all of the employees all recognized the root of the problem was driven by multiple violations of their dignity, what they wanted in order to restore the relationship with management was to hear from them an expression of remorse for what they had done. It never happened.

It never happened, but not without a tremendous effort on my part to get the senior leadership team to understand how powerful it would be if they would at least acknowledge the impact of their actions on the rest of the employees. Even though I never did the initial Dignity 101 sessions with the leadership team, I did develop a five-option document for them to help guide them with a "dignified" approach to the executive compensation problem. The five options were as follows:

- Option 1: Acknowledgment that their decision to take the bonuses felt like a dignity violation to the employees. "We would like to take this opportunity to let you know that we are aware that there is an historical grievance regarding the pay out of executive compensation in 2006. We recognize that at the time, when we asked you to "pull together and win together," by taking the pay out, it felt to you like a betrayal of that agreement and that it felt unfair. We also recognize that it felt to you like we did not consider what the impact would be on our agreement and our relationship."

- Option 2: Acknowledgment with expression of remorse. "We would like to take this opportunity to let you know that we are aware that there is an historical grievance regarding the pay out of executive compensation in 2006. We recognize that at the time, when we asked you to "pull together and win together," by taking the pay out, it felt to you like a betrayal of that agreement and that it felt unfair. We also recognize that it felt to you like we did not consider what the impact o would be on our agreement and our relationship." We feel bad that by taking the payout, you felt betrayed and that the actions were unfair, and that you felt we didn't consider the impact on you."

- Option 3: Acknowledgement with Apology. ."We would like to take this opportunity to let you know that we are aware that there is an historical grievance regarding the pay out of executive compensation in 2006. We recognize that at the time, when we asked you to "pull together and win together," by taking the pay out, it felt to you like a betrayal of that agreement and that it felt unfair. We also recognize that it felt to you like we did not consider what the impact o would be on our agreement and our relationship." We feel bad that by taking the payout, you felt betrayed and that the actions were unfair, and that you felt we didn't consider the impact on you. We would like to apologize for making you feel that way."

- Option 4: Acknowledgment with Apology and Admission of Guilt. "We would like to take this opportunity to let you know that we are aware that there is an historical grievance regarding the pay out of executive compensation in 2006. We recognize that at the time, when we asked you to "pull together and win together," by taking the pay out, it felt to you like a betrayal of that agreement and that it felt unfair. We also recognize that it felt to you like we did not consider what the impact o would be on our agreement and our relationship." We feel bad that by taking the payout, you felt betrayed and that the actions were unfair, and that you 
felt we didn't consider the impact on you. We would like to apologize form making you feel that way." We realize that we made a mistake and that it damaged our relationship."

- Option 5: Acknowledgment with Apology, Admission of Guilt, and Commitment to Change the Behavior. "We would like to take this opportunity to let you know that we are aware that there is an historical grievance regarding the pay out of executive compensation in 2006. We recognize that at the time, when we asked you to "pull together and win together," by taking the pay out, it felt to you like a betrayal of that agreement and that it felt unfair. We also recognize that it felt to you like we did not consider what the impact o would be on our agreement and our relationship." We feel bad that by taking the payout, you felt betrayed and that the actions were unfair, and that you felt we didn't consider the impact on you. We would like to apologize form making you feel that way." We realize that we made a mistake and that it damaged our relationship. We would like to take action to rectify the situation and do it differently in the future."

In the end, I was unable to get the leadership team to consider even Option 1. They refused to do it. They continued with their position that they did nothing wrong. They would tell me that the employees were "just emotional" and they didn't want to enable their irrational behavior. They said to me, "If the unions were willing to be "rational" about the issue, we would engage with them-but in this case, we can't deal with highly emotional people."

In some ways, they were right. The employees were emotional. What the leadership team could not grasp was that these "emotional" reactions were the result of having endured multiple dignity violations. Instead of seeing that connection, they used the "emotions" to implicitly demonstrate that the employees were inferior and incapable of rationality. Being "emotional" should have been a red flag for the leadership team, leading to the question, "why are the employees reacting emotionally and what way are we responsible?" Another missed opportunity for learning.

In the final analysis, there were many other dignity issues that were contributing to the culture of indignity and distrust in the organization (failure to recognize the identities and roles of employees, lack of safety, recognition, understanding, acknowledgment, inclusion, etc.), but the systemic issue of perceived betrayal and fairness was at the core of the problem between the unions and management. Add to it the failure of management to hold themselves accountable for the impact on the employees, and one can see why the conflict endured for so long. The failure of the leadership team to use the dignity lens to understand the conflict ultimately resulted in the loss of their jobs and the company.

\section{Conclusion}

There were a lot of forces acting against the implementation of the Dignity Model in this organization. The most significant factor was that the senior executive leadership team was not on board from the beginning. I had serious concerns about this from the start, but because I was new to the corporate world, I took the advice of the consultant who had been working with the organization for years, instead of following my instincts. The Senior Vice President with whom I met in the beginning was reluctant to set up a meeting for me with the CEO and other members of the executive leadership team. That was a red flag, but I didn't feel I had the power to override his decision. I consider this my failure. I should have insisted on meeting with them. 
At the end of the 4-year project, the company was forced into a merger with another company in the industry. The failed relationship with the unions brought them down in the end. The unions ended up siding with the new company and virtually every member of the executive leadership team was asked to leave, including the CEO.

I strongly believe that if the senior VPs had been exposed to the Dignity Model, had made a commitment to acknowledge and redress the dignity wounds from the past, that there would have been a different outcome. Their failure to make themselves vulnerable by admitting that they had made a mistake with the bonuses was the coup de grace for them and the company.

\section{The Power of Self-Preservation Instincts}

What was it that prevented the management from at least acknowledging the impact of their decision on their employees? Why were they so reluctant to say that they had made a mistake?

I assume that part of the resistance to acknowledging a wrongdoing had to do with their fears of the financial impact on the company. While that likely played a role, it is my view that their greater concern was looking bad in the eyes of the world. The media was already covering the hostile dynamics that were taking place between the unions and management, and the company had suffered greatly by the bad press.

From a dignity perspective, their behavior was a textbook example of self-preservation instincts gone awry. The company violated the majority of the Ten Temptations to Violate Dignity (ways in which our unconscious, hard-wired instincts take over our decision-making under circumstances of threat). ${ }^{2}$ They took the bait and sought revenge when the unions challenged them; they failed to take responsibility for their actions; they tried to save face; they assumed they were the innocent victim in the failed relationship; they resisted feedback from the employees; they tried to shame and blame others to deflect their guilty; and they engaged in viscous gossip about the unions - all in an effort to not look bad in the eyes of the world.

The Ten Temptations to Violate Dignity are examples of how our self-preservation instincts are equipping us for survival, but are also getting in the way of more emotionally healthy responses to threatening circumstances. While these inherited instincts that first evolved to keep our early ancestors safe, they are ill equipped to handle relationship challenges in the $21 \mathrm{st}$ century. We do not have wild animals on our tails today, threatening our survival. In fact, they are creating more problems for us rather than protecting us. Today, we need the self-knowledge to recognize when we are caught in the trap that our evolutionary legacy has created for us. We need to know how to manage our instincts before they destroy our relationships.

The truth about the human experience is that our unconscious emotional world wants us to survive over anything else. Some neuroscientists tell us that $95 \%$ of our behaviors are driven by unconscious forces emanating from one of the most ancient parts of our brains (limbic system that controls our emotional reactions) (Mlodinow 2012). This part of the brain does not care about empathy, perspective taking, or considering the impact of our actions on others. All it cares about is eliminating the source of the threat. But as the eminent evolutionary biologist, Jerome Barkow, warns us, "Biology is not destiny unless we ignore it (Barkow 2006)." We are much more than our hardwired instincts, but we have to educate ourselves about how to manage them.

Without self-knowledge-an awareness and understanding of the pull of these internal, unconscious forces - we will continue to be a slave to them. Learning how to manage

\footnotetext{
${ }^{2}$ See Appendix
} 
them before they control us requires effort and discipline, just like any other kind of learning.

As leadership expert Ron Heifetz reminds us, there are two kinds of problems leaders face - ones that require technical fixes (like a new business plan, or a new contract, new technology) and those that require adaptive changes (Heifetz 1994). In other words, there are problems that require new learning; knowledge that helps us see the limits of what we know.

The leadership challenge the senior executives faced did not require a technical fix. It required deep learning about how to be in relationship with others, how to self-reflect, how to take responsibility for ones hurtful actions - all dignity related skills.

Social psychologist, Carol Dweck warns us of the danger of not keeping an open mind when it comes to learning, especially those in leadership positions (Dweck 2006). Her research demonstrates people who have a fixed mindset about what they know (certainty that they are "right"), make the worst leaders. Those with a growth mindset see "mistakes" as challenges to push the boundaries of what they know. They don't talk about having "failed", but instead, ask themselves, "How can I use this situation as a learning opportunity? What do I need to know to address this problem.?"

She also warns that leaders with a fixed mindset are often judgmental, deflecting responsibility when something goes wrong in an organization. This is exactly what the senior leadership team did when they claimed that the employees were "just emotional" and therefore, dismissing their concerns. They were not able to hold a mirror up to themselves and ask the question, "In what way might we be contributing to the problem with the unions?" The challenge they faced required something new from them. It required an understanding not only of themselves and the hardwired forces acting upon them, but equally as important, an understanding of human relations and how people want to be treated.

Matthew Lieberman, in his book, "Social: Why Our Brains are Hardwired to Connect," tells us that our brains are wired to be cared for, valued and treated fairly by others. It is a source of well being for us (Lieberman 2013). The actions of the executive leadership team did not signal to the employees that they were cared for and valued. The employees felt the opposite. Their outrage at being treated unfairly never dissipated. The resentment only grew among them. Lieberman cites research in his book that shows that leaders who have an understanding of what it takes to honor dignity and demonstrate care to their employees are those who are described as "great leaders" by employees. This is the kind of knowledge and learning that the leadership team needed. Instead of seeing their employees as valuable and worthy of care, they dismissed them as "irrational and emotional."

In retrospect, if I had had the opportunity to introduce the Dignity Model (Introduction to Dignity "101") to the senior leadership team-giving them the tools to dis-empower their powerful self-preservation forces within them - they might have been able to extend the desperately needed acknowledgment to the unions. Their leadership failure was a failure to recognize when they needed new learning. The Dignity Model could have provided them with the insight and skills that were profoundly lacking in their team.

What was my learning after working with this organization?

1. Always start an intervention at the top. Be sure there is agreement by the key decision makers that dignity is playing a powerful role in the organization and that dignity knowledge is necessary to address the human centered problems at the core of most failed relationships.

2. Always start with the Dignity 101 seminar. Assume that everyone needs a lesson in dignity. While most people perpetrate dignity violations on a daily basis, they do not do it 
to be hurtful or vindictive. Most people simply haven't had the exposure to dignity learning. They often do not know what they don't know.

3. Learning about dignity increases our emotional capacities. At the core of dignity-based conflicts are deep emotional wounds. Our instinctive, amygdala-driven default reactions to dignity violations create a cycle of indignity. Equipping people with dignity skills that focus on re-calibrating our default responses from self-preservation to responsibilitytaking is at the core of the emotional work.

4. An organizational culture is only as dignified as their leaders. Leaders with dignity skills and knowledge set the tone of an organization and model the behaviors that are needed to promote a sense of employee engagement and well-being.

My final reflection is that people who lead with dignity end up with not only an internal culture where employees and management alike experience a sense of well being and fulfillment, but with a dignified company with its face to the world. People are yearning for a new narrative about what humans are capable of, and dignity might just show us the way.

\section{Questions for Discussion}

1. What are the dangers of confusing dignity and respect?

2. What needs to change in the traditional business models to keep up with this new understanding of what human beings need to feel valued in the workplace?

3. What steps need to be taken to integrate dignity consciousness to business leaders?

4. What do you see as the major obstacles to creating a culture of dignity in the workplace?

\section{Appendix}

\section{Essential Elements of Dignity}

"Treat people as they want to be and you help them become what they are capable of being."

Johann Wolfgang von Goethe

- Acceptance of Identity - Approach people as neither inferior nor superior to you; give others the freedom to express their authentic selves without fear of being negatively judged; interact without prejudice or bias, accepting how race, religion, gender, class, sexual orientation, age, disability, etc. are at the core of their identities. Assume they have integrity.

- Recognition-Validate others for their talents, hard work, thoughtfulness, and help; be generous with praise; give credit to others for their contributions, ideas and experience

- Acknowledgment - Give people your full attention by listening, hearing, validating and responding to their concerns and what they have been through 
- Inclusion-Make others feel that they belong at all levels of relationship (family, community, organization, nation)

- Safety - Put people at ease at two levels: physically, where they feel free of bodily harm; and psychologically, where they feel free of concern about being shamed or humiliated, that they feel free to speak without fear of retribution

- Fairness-Treat people justly, with equality, and in an evenhanded way, according to agreed upon laws and rules

- Independence - Empower people to act on their own behalf so that they feel in control of their lives and experience a sense of hope and possibility

- Understanding - Believe that what others think matters; give them the chance to explain their perspectives, express their points of view; actively listen in order to understand them

- Benefit of the Doubt-Treat people as trustworthy; start with the premise that others have good motives and are acting with integrity.

- Accountability - Take responsibility for your actions; if you have violated the dignity of another, apologize; make a commitment to change hurtful behaviors

From: Dignity: Its Essential Role in Resolving Conflict, Yale University Press, Donna Hicks

${ }^{1}$ Copyright (C) 2011 by Donna Hicks. All rights reserved.

\section{The Ten Temptations Violate Dignity}

(How to maintain your dignity when your instincts think they know better)

1. Don't Take the Bait: Don't let the bad behavior of others determine your own. Restraint is the better part of dignity. Don't justify returning the harm when someone has harmed you. Do not do unto others as they do unto you.

2. Don't get caught in the temptation to save face: Don't lie, cover up, deceive yourselftell the truth about what you have done.

3. Don't shirk responsibility when you have violated the dignity of others. Admit that you made a mistake and apologize for hurting them.

4. Don't be lured by false dignity: Beware of the desire for external recognition of your dignity in the form of approval and praise. If we depend on others alone for validation of our worth - we are seeking false dignity. Our dignity also comes from within.

5. Don't be lured by false security. Don't let your need for connection compromise your dignity. If we remain in a relationship where our dignity is routinely violated, our need for connection has outweighed our need to maintain our own dignity.

6. Don't just sit there and take it! Don't allow someone to violate your dignity without saying something. Stand up for yourself. Don't avoid confrontation. A violation is a signal that there is something in the relationship that needs to change.

7. Don't assume you are the innocent victim in a troubled relationship: Open yourself to the idea that you might be contributing to the problem. You may not be aware of it. We need to be able to look at ourselves from an outside perspective so that we can see ourselves as others see us.

8. Don't resist feedback from others. We often don't know what we don't know. We all have blind spots (ways that we unconsciously behave that are undignified). We need to 
overcome our self-protective instincts to resist constructive criticism and consider feedback as a growth opportunity.

9. Don't blame and shame others to deflect your guilt. Get control of the urge to defend yourself by trying to make others look bad.

10. Don't be lured by false intimacy. Beware of the tendency to connect with others by gossiping about someone else. Being critical and judgmental about others when they are not present can feel like a bonding experience and makes for engaging conversation but it is harmful and undignified. If you want to create intimacy with others, speak the truth about yourself - about what is really happening in your inner world - and invite the other to do the same.

From: Dignity: Its Essential Role in Resolving Conflict, Yale University Press, Donna Hicks

${ }^{1}$ Copyright (C) 2011 by Donna Hicks. All rights reserved.

\section{References}

Barkow, Jerome. 2006. Missing the revolution: Darwin for social scientists. Oxford: Oxford University Press. Dweck, Carol. 2006. Mindset: the new psychology of success. New York: Ballantine Books.

Heifetz, Ronald. 1994. Leadership without easy answers. Cambridge: Harvard University Press.

Hicks, Donna. 2011. Dignity: its essential role in resolving conflict. New Haven: Yale University Press. Lieberman, Matthew. 2013. Social: why our brains are hardwired to connect. New York: Crown Publishers. Mlodinow, Leonard. 2012 Subliminal: how your unconscious mind rules your behavior. New York: Vintage Books. Sheff, Thomas J., and Suzane M. Retzinger. 1991. Emotions and violence: shame and rage in destructive conflicts. Lexington: Lexington Books. 